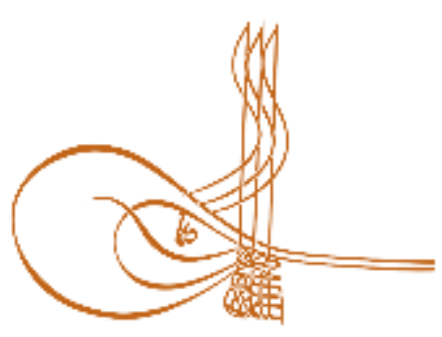

www.turkishstudies.net/social
Turkish Studies - Social Sciences

eISSN: $2667-5617$

Research Article / Araștırma Makalesi

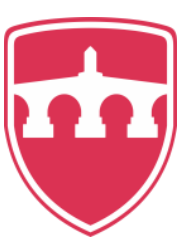

INTERNATIONAL

BALKAN

UNIVERSITY

Sponsored by IBU

\title{
Türk Spor Tarihinde Geleneksel Türk Sporkarı Ve Çorumlu Sporcular - Asamblaj Tekniği İle Sanatsal Sunumu-"
}

\author{
Corum Sportsmen and Traditional Turkish Sports in the History of Turkish Sport - Artistic \\ Presentation with Assemblage. Technique-
}

\author{
Faruk Yamaner* - Saliha Ağaç** - Mücella Baylavlı***
}

\begin{abstract}
This research was made in order to determine the sports branches that have an important place in Turkish history from past to present and the general characteristics of these sports branches, to get to know and to introduce the athletes from Çorum, who have been successful in these sports branches. For this purpose, the research was carried out in two main stages:
\end{abstract}

1. Determining sports branches that have an important place in Turkish history and the general characteristics of these sports branches.

2. Determining the athletes who left their mark with their successes in various sports branches and preparing the assemblies of the visuals of the athletes.

In the literature search, no studies were found about the athletes from Çorum who left mark to Turkish sports history. It is considered that this research, will contribute to the introduction of the sport branches that are specific to Turks, which are important parts of our culture, and their features as well as recognition and introduction of athletes from Çorum who left mark with their successes.

This research is a descriptive research and the determination of the current situation was made by means of archive scanning. Sports branches with an important place in Turkish history from the past to the present and

${ }^{*}$ Çalışmada kullanılan veriler 2019 yılına aittir.

* Prof. Dr., Hitit Üniversitesi, Spor Bilimleri Fakültesi, Antrenörlük Eğitimi Bölüm

Prof. Dr., Hitit University, Faculty of Sport Sciences, Coaching Education Department

ORCID 0000-0002-2302-8650

yamanerf@hotmail.com

** Prof. Dr., Ankara Hacı Bayram Veli Üniversitesi Sanat ve Tasarım Fakültesi, Moda Tasarımı Bölümü

Prof. Dr., Ankara Hacı Bayram Veli University Faculty of Art and Design, Department of Fashion Design

ORCID 0000-0003-2507-2361

asaliha@gazi.edu.tr

*** Öğr. Gör., Hitit Üniversitesi Teknik Bilimler Meslek Yüksekokulu, Tasarım Bölümü

Lec., Hitit University Vocational School of Technical Sciences, Department of Design

ORCID0000-0002-2072-3244

mucellabaylavli@hitit.edu.tr

Cite as/ Atıf: Yamaner, F. Ağaç, S., Baylavlı, M. (2020). Türk spor tarihinde geleneksel Türk sporkarı ve Çorumlu sporcular - asamblaj tekniği ile sanatsal sunumu-, Turkish Studies - Social, 15(3), 1643-1657. https://dx.doi.org/10.29228/TurkishStudies.42045

Received/Geliş: 06 March/Mart 2020

Accepted/Kabul: 25 April/Nisan 2020

Copyright (C) INTAC LTD, Turkey 
the general characteristics of these sports branches were determined. Turkish National Olympics Committee and which plays the role of an archive was scanned with the aim of recognizing and introducing the athletes from Çorum who were successful in these sports branches due to the fact that it is the only reachable source on this subject. After the scan of the archive, four athletes from Çorum, who represented our country in the international arena in the wrestling branch and who redounded our country the Olympic medal, were selected. These assemblies were framed and was made ready for presentation. The résumés of these athletes were printed on a board and was made ready for presentation together with the assemblies.

Structured Abstract: This research was made in order to determine the sports branches that have an important place in Turkish history from past to present and the general characteristics of these sports branches, to get to know and to introduce the athletes from Çorum, who have been successful in these sports branches. For this purpose, the research was carried out in two main stages:

1. Determining sports branches that have an important place in Turkish history and the general characteristics of these sports branches.

2. Determining the athletes who left their mark with their successes in various sports branches and preparing the assemblies of the visuals of the athletes.

It is aimed to introduce these sports branches and athletes as an archive, to be an example for future generations and to be a source of inspiration for their successes by displaying the prepared collages permanently in suitable places. The root of the word sport comes from Latin. The word 'disport / desport', which means distributing, separating, has changed to 'sport' over time and spread throughout the world (Emiroğlu, 2001, p.555). Today, sports; which is based on struggle, competition and prevailing, It is the struggle of the individual to prevail over himself, his opponent or time by using his mind and body abilities. Sport is a cultural, social, psychological and physical phenomenon. The historical development of sport has developed in parallel with the history of humanity. The historical development of sport has developed in parallel with the history of humanity. The movements, which we now call sports branches, emerged from the movements made in the early ages to be protected and to ensure their own safety. The historical development of sport has developed in parallel with the history of humanity.

The history of sports of Turks is examined in two stages: Traditional sports and modern sports.

Modern sports, universal language, production / consumption model, effective economy and industry in the world, wide participation of fans, democratic and comprehensive organization, visual quality it brings to the fore, unique facility and material, high performance imperative before and after the competition, technical knowledge and It differs from traditional sports due to many other factors such as equipment requirement.

Compared to the sports organizations of today, traditional sports organizations, which have survived by some changes from past practices, have observed some changes and transformations in the characteristics of modern sports between past practices and today (Karahüseyinoğlu, 2008: 2). Sports branches with federation in our country can be listed as follows: Karate, Athletics, Rowing, Basketball, Horse Riding, Cycling, Boxing, Ice hockey, Ice skating, Gymnastics, Field hockey, Fencing, Football, Wrestling, Golf, Skiing, Sledding, Judo and lead, Weightlifting, Handball, Table tennis, Canoeing and Rafting, Badminton, Water polo, Modern pentathlon, Archery, Rugby, Swimming, Taekwondo, Tennis, Triathlon, Volleyball, Sailing, Bowling, Bridge, Bowling, Darts, Billiards, Mountaineering, Kickboxing, Orienteering, Shooting, Motorcycle, Muay thai, Automobile sports, Underwater sports, Wush.

This research is a descriptive research and the determination of the current situation was made by means of archive scanning. Sports branches with an important place in Turkish history from the past to the present and the general characteristics of these sports branches were determined. Also "100th Anniversary of National Olympic Committee of Turkey" which was issued for the 100th year of the Turkish National Olympics Committee and which plays the role of an archive was scanned with the aim of recognizing and introducing the athletes from Çorum who were successful in these sports branches due to the fact that it is the only reachable source on this subject. After the scan of the archive, four athletes from Çorum, who represented our country in the international arena in the wrestling branch and who redounded our country the Olympic medal, were selected. The visuals of these athletes were found and illustration works were made on the visuals. The visual data obtained were printed with a size of $100 \times 70 \mathrm{~cm}$. First, paper perspective (paper relief) was performed on the print-outs, then the garment dressing was carried out on the picture and the 
artistic application works were completed with the assemblage technique of the images. These assemblies were framed and was made ready for presentation. The résumés of these athletes were printed on a board and was made ready for presentation together with the assemblies.

To determine the sports branches that have an important place in Turkish history from past to present and the general characteristics of these sports; The results of this research, which was conducted in order to get to know, introduce and keep athletes who are trained in Çorum, and who have left their mark in Turkish sports history, are as follows:

$>$ Turks have a very rooted sports culture.

$>$ The nomadic culture, necessity of survival, hunting and fighting cultures in Turks have caused the sport to develop continuously from ancient times.

$>$ Equestrian sports have developed due to the high use of the horse in the nomadic culture and social life of the Turks.

$>$ Turks have made the game more active by including it in their social and entertainment life instead of using it only as a war tactic and preparation.

$>$ Sports history of Turks has two stages:

Traditional sports: Traditional wrestling (aba wrestling, shalwar wrestling, karakucak wrestling, oily wrestling, belt wrestling), traditional equestrian sports (horse riding, horse racing, rahvan horse racing, javelin, polo, gökbörü), traditional sled racing, archery, hunting, spear, pinpointing, lift up, matrak, tomak.

Modern sports: Karate, Athletics, Rowing, Basketball, Horse Riding, Cycling, Boxing, Ice hockey, Ice skating, Gymnastics, Field hockey, Fencing, Football, Wrestling, Golf, Skiing, Sledding, Judo and lead, Weightlifting, Handball, Table tennis Canoeing and Rafting, Badminton, Water polo, Modern pentathlon, Archery, Rugby, Swimming, Taekwondo, Tennis, Triathlon, Volleyball, Sailing, Bowling, Bridge, Bowling, Darts, Billiards, Mountaineering, Kickboxing, Orienteering, Shooting, Motorcycle, Muay thai, Automobile sports, Underwater sports, Wush.

$>$ It has not been able to survive until today in traditional sports or has undergone change.

$>$ The athletes who have been reached within the scope of the research, selected among the athletes who have achieved international achievements in their field, and whose artistic assembly studies have been decided to be carried out are: Tevfik Kış, Nazmi Avluca, Adil Candemir, Mahmut Atalay.

$>$ As a result of the artistic assemblage works prepared during the research, the following works were obtained.

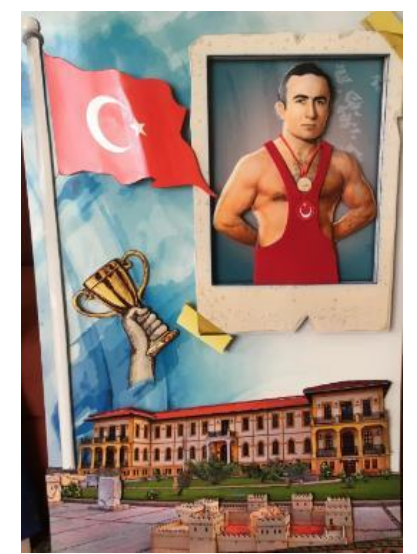

MAHMUT ATALAY

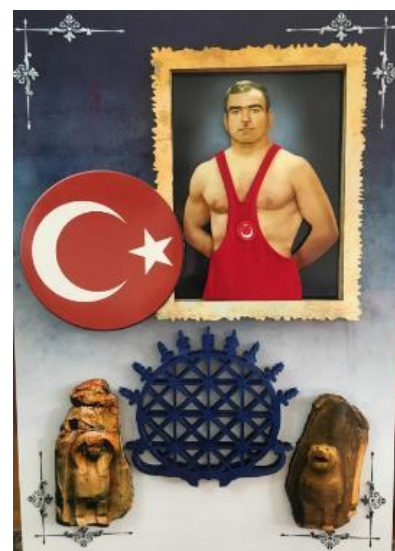

ADİL CANDEMIR

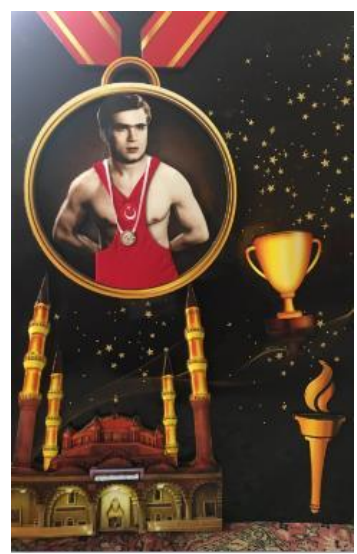

TEVFIKK KIŞ

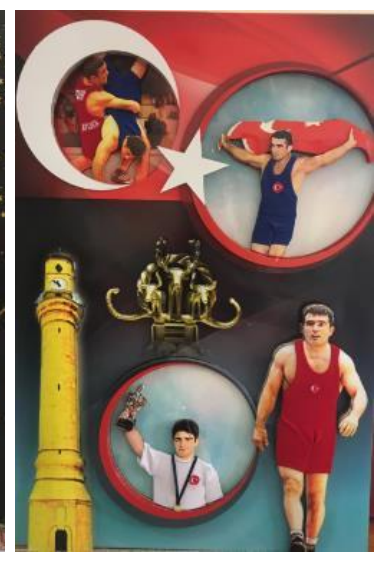

NAZMİ AVLUCA

Sport is one of the complementary elements of our culture. Sport is a socially effective educational element. Especially young generations have a great contribution to their constructions, creatives and 
producers, to increase their success, social cohesion and cultural development. Sports is one of the important indicators of the educational and cultural levels of societies. It is suggested to carry out similar studies on different traditional Turkish sports and athletes in future studies. Thus, recalling and keeping alive one of our important cultural heritages, Turkish sports and successful Turkish athletes; It is believed that it will contribute both to the promotion of cultural heritage in the national and international arena, and also to inspire the young generation's ancestors to step into new successes.

Keywords: Corum, sports, wrestling, Olympic, assemblage.

Öz: Bu araştırma; geçmişten günümüze Türk tarihinde önemli yere sahip spor dalları ve bu sporların genel özelliklerini belirlemek, bu spor dallarında, başarıları ile iz bırakan Çorumlu sporcuları tanımak ve tanıtmak amacıyla gerçekleştirilmiştir. Bu amaçla, araştırma iki ana aşamada gerçekleştirilmiştir:

1. Türk tarihinde önemli yere sahip spor dalları ve bu sporların genel özelliklerinin belirlenmesi.

2. Çeşitli spor dallarında başarıları ile iz bırakan Çorumlu sporcuların belirlenerek sporculara ait görsellerin üzerinde asamblaj tekniği ile sanatsal sunumların hazırlanması.

Literatür taramalarında, Türk spor tarihine iz bırakan Çorumlu sporculara ilişkin herhangi bir çalışmaya rastlanmamıştır. $\mathrm{Bu}$ araştırma, betimleyici bir araştırma olup, araştırmanın amacı doğrultusunda arşiv taraması yolu ile mevcut durumun tespiti yapılmıştır. Geçmişten günümüze Türk tarihinde önemli bir yere sahip olan spor dalları ve bu spor dallarının genel özellikleri belirlenerek, bu spor dallarında başarılı bir serüven ortaya koyan Çorumlu sporcuları tanımak ve tanıtmak amacıyla; bu konuda ulaşılabilen basılı tek kaynak olması nedeniyle, 'Türkiye Milli Olimpiyat Komitesi'nin 100. Yılı' adlı kitap taranmıștır. Yapılan arşiv taramasının ardından güreş branşında ülkemizi uluslararası platformda temsil eden, ülkemize olimpiyat madalyası kazandıran dört Çorumlu sporcu seçilmiştir. Bu sporcuların özgeçmişleri bir pano halinde basılarak asamblajlar ile birlikte sunuma uygun hale getirilmiştir.

Anahtar Kelimeler: Çorum, spor, güreş, Olimpiyat, asamblaj.

\section{Giriş}

Spor sözcüğünün kökü, Latince'den gelir. Dağıtmak, ayırmak anlamına gelen 'disport / desport' sözcüğü zaman içinde 'sport' olarak değişmiş ve dünyaya yayılmıştır (Emiroğlu, 2001, s.555).

Günümüzde ise spor; temelinde mücadele, rekabet ve üstün gelmek olan, akıl ve vücut yetileri kullanılarak kişinin, kendine, rakibine ya da zamana karşı üstün gelme mücadelesidir. Spor kültürel, sosyal, psikolojik ve fiziksel bir olgudur. Sporun tarihi gelişimi, insanlık tarihi ile paralel gelişim göstermiş̧tir. Şu anda spor dalları olarak adlandırdığımız hareketler ilk çağlarda korunmak ve kendi güvenliğini sağlamak için yapılan hareketlerden ortaya çıkmıştır.

İnsanoğlunun dünya üzerinde var olduğu andan itibaren, kimi zaman bir zorunluluk kimi zaman bir eğlence için olsa da, sporla her zaman iç içe olduğu söylenebilir. İnsanların başlangıçta, hayatta kalabilmek için doğaya uyum sağlamak amacıyla yaptığ spor, beden sağlığını güçlendirerek savaşlarda üstün başarılar elde etmelerini sağlamıştır. Sonraları sporun insanların beden ve ruh sağlığına olan olumlu katkısı ve insanlar arasında sevgi, hoşgörü ve barışın oluşmasındaki önemi anlaşılmıştır ve spor toplumsal bir boyut kazanmıştır.

$\mathrm{Bu}$ araştırmanın amacı; geçmişten günümüze Türk tarihinde önemli yere sahip spor dalları ve bu sporların genel özelliklerini belirlemek; Çorumlu olup, ilgili spor dalındaki başarıları ile Türk spor tarihinde iz bırakmış sporcuları tanımak, tanıtmak ve yaşatmaktır. Araştırmanın kapsamı aşağıdaki iki aşamadan oluşmaktadır:

1. Literatür taraması yapılarak Türk tarihinde önemli yere sahip spor dalları ve bu sporların genel özellikleri belirlenmiştir. 
2. Arşiv taraması yolu ile çeşitli spor dallarında başarıları ile iz bırakan Çorumlu sporcular belirlenmiş ve bu sporculara ait görsellerin asamblajları hazırlanarak sanatsal sunumları yapılmıştır.

Hazırlanan asamblajların, uygun mekanlarda kalıcı olarak sergilenmesi ile, bir arşiv niteliğinde bu spor dallarının ve sporcuların gelecek nesillere tanıtılması, gelecek nesillere örnek teşkil etmesi ve başarılarında ilham kaynağı olması da hedeflenmektedir.

\section{Materyal ve Yöntem}

$\mathrm{Bu}$ araştırma, ilgili konu ya da etkinliğin etraflı ve detaylı bir şekilde tanımlanmasını ya da tasvirini elde etmeyi amaçlayan betimleyici bir araştırmadır. Araştırmanın amacı doğrultusunda, betimsel araştırma yöntemlerinden biri olan tarama metodu kullanılarak, var olan belge ve kaynakların incelenmesi yapılmış, konu ile ilgili mevcut durum ortaya konulmuştur.

Bu projede uygun bir alanda daimi olarak sergilenmek üzere; farklı spor dallarından Türk spor tarihine iz bırakmış Çorumlu sporcuların görselleri üzerine asamblaj çalışması yapılmıştır. Bu amaçla; spor dalları ve sporcular hakkında bilgi ve görseller saptamak için, yazılı ve görsel kaynaklar 1şığında arşiv taraması yapılmıştır. Tespit edilen sporcuların yüksek çözünürlüklü fotoğrafları bask1 tekniği ile büyütülmüştür. Sporcuların üzerindeki kıyafetler, sergilenecek fotoğraftaki boyutları saptanarak kalıpları çıkarılmış ve uygun dokudaki kumaş ve malzemelerle sporcuların bire bir kıyafetleri yapılmıştır. Daha sonra dikilen bu kıyafetler, çeşitli teknikler ile fotoğrafa giydirilmiștir. Kıyafetlerin üç boyutlu olması gereken bölümlerine rölyef, kabartma, kolalama ve spreyleme gibi tekniklerle, hacim kazandırılmıştır. Giydirilen fotoğraflar, kıyafetin hacmindeki genişlikler ve derinlikler dikkate alınarak çerçevelenmiştir.

\section{Bulgular ve Tartışma}

Araştırmanın amacı doğrultusunda yapılan literatür taramalarında ulaşılan, geçmişten günümüze Türk tarihinde önemli yere sahip spor dalları ve bu sporların genel özelliklerine ilişkin bilgiler aşağıda verilmiştir:

Sporun tarihi gelişimi, insanlık tarihi ile paralel gelişim göstermiştir. Şu anda spor dalları olarak adlandırdığımız hareketler ilk çağlarda korunmak ve kendi güvenliğini sağlamak için yapılan hareketlerden ortaya çıkmıştır.

İlk çağlardan kalma bazı resimler, spor dallarının ilk çağlardan itibaren gelişmeye başladığını göstermektedir. Ancak, spor tarihinin başlangıcı olarak adlandırdığımız resimlerin çoğu savaş ile yakından ilgilidir. Avını yakalamak veya düşmandan kaçmak için koşma, atlama, tırmanma gibi başlangıçta kendini koruma içgüdüsüyle ilgili faaliyetler sporla atletizmin çeşitli dalları olarak geçmiştir. İnsanların başka kişiler ya da hayvanlarla, araca gerek duymadan doğrudan beden güçleriyle yaptıkları mücadele ise güreşin, boksun doğmasına neden olmuştur. Ok, kılıç, mızrak, gürz, cirit, ve avcılık gibi savunma ile ilgili ya da kayık, kızak, kayak gibi insanı doğaya egemen kılacak çeşitli araçlar yapılmış, geliştirilmiştir (Günönü, 2015: 7).

Türk tarihinde ise eski çağlarda spor kültürü hakkında bilgilere Manas ve Dede Korkut Destanlarındaki yarışma ve yarıştırmalardan, Yenisey Mezar Kitabeleri, Orhun Abideleri gibi kaynaklardan ulaşabilmektedir. Türkler, Endüstriyel devrimin çok öncesinde, savaşların beden gücüne dayalı olduğu çağlardan beri savaşmışlardır. Bu yüzden de savaş öncesi hazırlık mahiyetinde sporları uygulamışlardır. Türklerin göçebe kültürü ve sosyal hayatlarında da atı çok fazla kullanmalarından dolayı, atlı sporlarda gelişmişlerdir. Ayrıca sporu sadece savaş taktiği ve hazırlığı olarak kullanmak yerine sosyal ve eğlence hayatına da dahil ederek oyunlaştırmışlardır. Dügün törenlerinde ve geleneklerinde pek çok müsabaka tertip etmişlerdir.

Türkler, ad verme işlemi ile kahramanlıkla/sporculukla özleştirmişler ve bütünleştirmişler, kişilikler ve moral değerler üzerinde etkili olacak gelenekler oluşturmuşlardır. Türk spor tarihi, 
büyük rekorlar, başarılar ve spor kahramanları ile doludur. Türk sporcuların kırdığı rekorlar için dikilen menzil taşları günümüze kadar gelmiştir. Türk milletinin sosyal ve sporculara karş1 duydukları sevgi ve saygıya dair pek çok örnek bulunmaktadır. Türk sultanları, okçuluk sporları için 'ok meydanları' tesis ettirmişler ve rekorlar kırarak menzil taşları dikmişlerdir. Türklerde sporun geniş bir kültürel tabana yayılması ve kurumlaşması erken dönemlerden getirdiği birikimin yanında, devletin kendi spor politikasından da kaynaklanmaktadır (Güven,1992, s.272). sporlar.

Türklerin spor tarihini iki aşamalı olarak incelenmektedir: Geleneksel sporlar ve modern

\section{Geleneksel Türk Sporları}

Geleneksel sporlar; günümüze kadar gelmeyi başaramamış ya da değişime uğramış kültürümüze özgü, kültürümüzü yansıtan sporlar olarak adlandırılır.

Mezopotamya ve Anadolu coğrafyasında yapılan arkeolojik kazılarda, Türklerin savaş eğitimi veren sporları yaptıkları tespit edilmiştir. Bunlar; güreş, k1lıç, okçuluk, at yarışı, çöğen/polo, cirit, mızrak, gökbörü, seyirtme, avcılık, pujila/boks, matrak, tomak, ağırlık kaldırma vb (Fişek, 1985:26). Bazı yarışlarda geleneksel kıyafetler ve malzemeler kullanılır. Atlı cirit ve atlı rahvan yarışında şalvar, yelek; şalvar güreşinde kısa şalvar, karakucak güreşinde ise pitpıt vb kıyafetlerin giyilmesi buna örnek verilebilir (Karahüseyinoğlu, M. F. 2012: 94.)

\subsection{Geleneksel Güreşler}

En eski spor dallarından biri olan güreşin, insanın kendini korunmaya yönelik olarak yaptığı; tutma, atma ve boğma gibi bedensel faaliyetlerinin zamanla karşılıklı kuvvet yarışına dönüşmesi ile ortaya çıktığı düşünülmektedir ( Polga, İ. 1998: 2). Güreş, karş1lıklı iki kişinin birbirine üstünlük sağlamak için, kas gücünü kullanarak belli kurallar çerçevesinde, rakibinin sırtını yere getirerek yenmeyi amaçlayan bir spor türüdür. (Toyga, Y. 1990: 23).

Güreş en eski ata sporlarımızdandır. Pehlivanlık, kahramanlık ve güç göstergesi olarak görülmektedir. Türkiye'de geleneksel sporlar ikiye ayrılır:

1. İlgili federasyona bağlı olarak yürütülen resmi müsabakalar

2. Yerel yönetimlere bağlı olarak yürütülen mahalli organizasyonlar

Aşağıda geçmişten günümüze ülkemizin farklı yörelerinde farklı isimlerle oynanan geleneksel güreş çeşitleri verilmiştir:

\section{a. Aba Güreşleri}

Gaziantep ve Hatay'da yaygın olan bir güreş türüdür. Mahalli bir güreş türüdür. Rusya'daki 'sambo' güreşlerine benzemektedir. Adını pehlivanların giydiği abadan almıştır. Aba; yakasız, uzun, bol, kısa kollu, kaba ve kalın üst giysidir (Güven. Ö, 1992: 27).

\section{b. Şalvar Güreşleri}

Kahramanmaraş'a özgü bir güreş türüdür. Bütün güreş ayakta yapılır. Güreşçiler, müsabaka esnasında bol bir şalvar giyerler; üstleri ise çıplak kalır (Gürsoy, Ö. 1996: 17)

\section{c. Karakucak Güreşleri}

Müsabakaların, düz bir çayır ya da çimende yapıldığı geleneksel güreşlerdendir. Güreşçilerin üstleri çıplaktır, altlarına ise 'pıtpıt' adı verilen kısa bir pantolon giyerler. Karakucak güreşi, yağlı güreşe benzemektedir; fakat vücuda yağ sürülmeden güreşilir. Alta giyilen pitpıtlar; siyah kıldan örülmüş bir kumaştan dikilen, dar ve kısa bir şalvar türüdür. Karakucak güreşleri; Kahramanmaraş, Amasya, Tokat, Samsun, Çorum, Sivas, Erzincan, Erzurum ve Yozgat'ta 
yapılmaktadır. Günümüzde uluslararası düzeyde uygulanan minder güreşinin atasıdır (Gürsoy, Ö. 1996: 17).

\section{d. Yağlı Güreşler}

Kırkpınar güreşleri olarak da anılır. Kutlamalarda tören ve șenlik havasında yapılır. Tüm geleneksel sporlarımızda olduğu gibi yağlı güreşlerin de temelinde dostluk, kardeşlik ve yiğitlik yatar. bu güreş türü, diğerlerinden farklı olarak Türkiye Güreş Federasyonu'na bağlı olarak faaliyetlerini yürütür. Ülkemizde en fazla ilgi gören güreş türlerindendir. Ülkemizin pek çok yerinde yapılmakla birlikte, daha çok Ege, Marmara ve Karadeniz bölgelerinde ilgi görmektedir (Gürsoy, Ö. 1996: 17). Yağlı güreşte pehlivanlar kıspet denilen deriden yapılmış, kısa ve dar pantolonlar giyerler. Müsabaka esnasında vücutlarına yağ sürerler (Karahüseyinoğlu, M. F. 2012: 100). Yağlı güreşlerin en önemlisi, her yıl Edirne'nin Sarayiçi mevkisinde yapılan geleneksel 'Kırkpınar' yağlı güreşleridir (Bıyıklı, Y. 1993: 16-18).

\section{e. Kuşak Güreşleri}

Hıdırellez ve düğ̈̈nlerde, gelinin gelişinden sonra yapılan, Kırım Türklerine ait bir gelenektir. Kırım Türklerinde baharın gelişini kutlamak, kış mevsiminin miskinliğini üzerlerinden atmak için adına 'tepreş' denilen eğlenceler düzenlerlerdi. Bu törenlerde, davul ve zurnalarla, otlak veya çayırların üzerinde kuşak güreşleri yapılmaktadır (Karahüseyinoğlu, M.F. 2012: 104.)

\subsection{Geleneksel Atlı Sporlar}

Türklerin siyasal, dinsel, ekonomik, ve toplumsal yaşamında atın merkeze yakın bir yerde olduğu söylenebilir. Atın evcilleştirilmesi ve günlük yaşamda sıklıkla kullanılması bunda en büyük etken olmuştur (Türkmen, M. 1996: 12).

\section{a. Binicilik}

Türklerde atın sosyal hayattaki yerinin çok fazla olması atlı sporların geliştirilmesine sebep olmuştur (Özbay, G. 1999: 191). Türkler, daha beşikte iken binicidir. Çocuk beşikte iken bacakları arasına konan bir odun parçası vardır ki bir binici, at üstünde nasıl oturursa çocuk da bu odun parçası üzerinde aynı vaziyettedir. Çocuk emeklemeye başlar başlamaz ya bir koyunun, ya da bir köpeğin üzerine tırmanır. Beş yaşına geldiği zaman, kardeşleriyle ve arkadaşlarıyla ata binmeye başlar. Çocuk sekiz yaşına gelince, artık tam bir binicidir. On iki yaşında ise, yabani atları bile emrine boyun eğdirecek şekilde maharetli bir binici olur (Kepecioğlu, K. 1935: 16-17).

\section{b. At Yarışları}

At yarışları, spor olarak Türkler' de çok eskiden beri yapılmaktadır. Çin'in ilk resmi tarihi sayılan 'Shihchi' adlı eserin 110. Bölümünde, Hunların o çağda, Asya'nın en cins ve uzun koşan atlarını yetiştirdiği belirtilmektedir (Ögel, B. 1989: 8) At yarışları, Türk Mitolojisi’ nin de önemli sahnelerinden birisi olmuştur. İki tür at yarışı vardı. Bunlardan birincisi, sırf 'yarışma' gayesi ile yapılan yarışlardır. $\mathrm{Bu}$ çeşit yarışma, düğünlerin, toyların, ölü aşlarının, şenliklerin başlıca süslerinden biridir. Diğer ikinci tür yarışlar ise, 'savaşma' gayesi ile yapılır (Ögel, B. 1989: 21).

\section{c. Rahvan At Yarışları}

Rahvan, atın özel bir koşma biçimidir. At, koşu esnasında, bir yöndeki ayaklarını aynı anda atar. Bu sırada binici rahatsız olmaz. Rahvan koşusunda amaç; üzerindeki biniciyi ve yükü en uzun mesafeye, en kısa zamanda biniciyi yormadan ve en az enerji harcayarak taşımaktır ( Karahüseyinoğlu, M.F. 2012: 106).

\section{d. Cirit}

Cirit, Türklerin gerek düğün, bayram, şenlik gibi eğlencelerinde davul zurna eşliğinde, gerekse Cuma namazları sonrasında oynanan geleneksel bir spordur (Gezder, N. 1998: 94). At 
üzerinde, ellerinde kurumuş meşe dalından yapılan, adına cirit denen sert bir sopa bulunan binicilerin, belli kurallar dahilinde oynadığı oyundur. Atlı Cirit oyununda sporcu karşı takıma kurallar içerisinde uzak mesafeden cirit atar. Kimi zaman cirit atmak karşı oyuncunun yaralanmasına sebep olabilir. Fakat rakibe aşırı yaklaşıldığında ve sıkıştıııldığında ise bağışlanıp başka bir sporcuya hamle yapılır. Oyun içerisinde her türlü sertliğe ve yaralanmalara rağmen oyun bitince kardeşlik yine eskisi gibi devam eder. Böylece cirit oyunu, sporcuya nefsine hâkim olmayı öğretmekte ve büyük bir savaşçı olarak eğitmektedir. Yakalayıp bağışlama ve kin tutmama Türk milletinin en büyük özelliklerindendir (Güleç 1996: 17; Sümer 1982: 1-2)

\section{e. Çöğen / Çevgan / Polo}

Asya'dan dünyaya yayılmış atlı bir top oyunudur. Polo sporunun başlangıcında, Doğu'daki savaşçı, mücadeleci şartlar, askeri hareketlilik ve Türklerin Hindistan'a inmesi 15.yy'da buradaki toplumun sinıflı yapısı, bu pahalı polo sporunun daha sonraları Batı zenginliğinin ve sömürgeciliğinin dikkatini çekmesi ve onlarla beraber Batı'ya geçmesine neden olmuştur (Ayan, D. 1997: 43). Çöğen / Polo oyunu mehter eşliğinde oynanmaktadır. Mehter siyasi gücün bir göstergesidir. Mehter aynı zamanda oyunda, savaşta, törende müzik çalma yetkisi bir siyasi otoriteye işaret etmektedir. Askeri amaçlı spor olan çöğenin son yüzyılda sadece sportif amaçla yapılması mehter gibi işitsel siyasi göstergeyi zorunlu kılmaktan kurtarmış görünmektedir (Güven, Ö. Ayan, D. 1996: 34). Çevgan oyununun amacı; sahanın iki tarafında olan kale direklerinden, at üstünde koşarken çevgan sopası ile çevgan topuna vurarak, topu geçirmektir.

\section{f. Gökbörü}

Türklerin en eski ve milli oyunlarındandır. Kazakistan'ın Seyhun bölgesinde bu oyun hala oynanmaktadır. Gökbörü atlı bir oyundur. At üstünde koşarken, bir gece önceden başı ve ayakları kesilip, içine saman doldurulup karnından dikilmiş ve bütün gece su içinde tutularak ağırlığ $30 \mathrm{~kg}$ kadar getirilmiş olan oğlağı kapmak için oynanır.

\subsection{Geleneksel Kızak Yarışları}

Türk boylarının kalkana benzeyen, at derisinden kızak yaptıkları bilinmektedir. Türklerin bu özel kızaklar ile dağlarda avlandıkları, yine aynı kaynaklara dayandırılır (Öngel, H. B. 2001: 85). Anadolu'nun çeşitli bölgelerinde kış aylarında kızak yarışları yapılmıştır. Geleneksel 'kayık' yarışları günümüzde uluslararası platformda 'luge' ve 'bob' kızak yarışları olarak uygulanmaktadır.

\subsection{Okçuluk}

Türkler, tarihleri boyunca ok kullanmaktaki ustalıkları ile tanınmışlardır. Göktürkler'in savaşlarda kullandıkları 'çavuş oku' adlı oklar çıkardıkları 1slık sesiyle düşmanı korkutmaktadır. Ayrıca çıkarılan sesin özelliğine göre haberleşmede de kullanılmaktadır. Ok ve yay Türklerde kutsal kabul edilmiştir. Türk sultanları, okçuluk yapılabilsin diye 'ok meydanları' inşa ettirmiş̧ir. Padişahların ve vezirlerin bu meydanlarda ok atmaları, rekor kırmaları bu sporu popüler kılmıştır. Okçuluk sporu Osmanlı Dönemi'nde kurumlaşmıştır. II. Mahmut Döneminde en parlak zamanlarını yaşamıştır. Günümüzde okçuluk modern sporlar içerisinde, federasyona bağlı olarak yürütülmektedir (Karahüseyinoğlu, 2012: 112).

\subsection{Avcilık}

Türkler; at besleyen, av peşinde koşan insanlardır. Av hayvanlarını izleyerek, uzun mesafeler kat etmişlerdir. Bütün bir boyun katıldığı büyük sürek avları tertiplemişlerdir. Deri veya kıl çadırlarda oturan, kımız içen ve hayvan besleyen eski Türkler; avcılığı, günlük hayatlarının bir parçası olarak görmektedirler. Beslenme ve ekonomileri, yarı yarıya avcılığa dayanmaktadır. Selçuklu Devleti döneminde Tuğrul Bey, avcılık teşkilatını resmi bir kurum haline getirmiştir. Osmanlı Devlet Teşkilatı'nda da avcılık resmi bir kurum olmuştur. Ordu içinde 'avcı birlikleri' yer almıştır (Şükrü, Y. 1987, 143).

Turkish Studies - Social, 15(3) 
Türkler avcılığı savaşa hazırlayıcı bir vasıta ve bir ön tatbikat olarak uygulamışlar ve savaşlardan önce harp taklidi niteliğinde büyük sürgün avları düzenlemişlerdir. Avcıllğın yanında atıc1lık ve binicilik de birlikte geliştiği için savaşta gerekli olan cesaret, beden gücü ve irade kuvveti gibi nitelikler bu sayede sürekli olarak güçlendirilmiştir (Huş, S. 1974: 14).

\subsection{Mizrak Oyunu}

Savaşta, süvariler tarafindan kullanılan mızrak / karg1 ya hedefe firlatılmak veya hedefe süratle at sürülerek hedefi delmek üzere kullanılmıştır (Alp, T. N. 1993: 251). Oyunun amac1 savaşa hazırlıktır. Karşı karşıya mücadele etme, isabet kaydetme ve mızrağ 1 en uzağa firlatmak esastır.

\subsection{Labut Atma}

Labut 80 - $90 \mathrm{~cm}$ uzunluğunda ve $4-5 \mathrm{~cm}$ kalınlığında kabuğu soyulmuş kuru meşe değneğidir. Uzağa ve yükseğe atılabilmesi, yaş ağaçlara saplanması için uç kısmı altı köşeli olarak sivriltilmiştir. Bu şekilde büyük bir kaleme benzediğinden 'kalemli' ismiyle anılmıştır. Ciritten farklılığ 1 , kısa ve kalın oluşudur. Tüfeğin kullanılmasından önce, binicilerin yanlarında taşıdığı bir savaş aracıdır. Küçük yaşlardan beri yaş ağaçlara ve kaplara saplayarak eğitim yapmış sporcu gençler ve cündiler savaşta düşmanını ve atını labut saplayarak düşürmüşlerdir. Tüfeğin yaygınlaşmasından sonra, önemini kaybetmiş ve yalnız cündilerin (Cündi: Osmanlıda hünerli biniciler için kullanılan sıfat) spor gösterilerinde ve yarışmalarında kullanılan bir spor aracı haline gelmiştir (Kahraman, A. 1995: 616.).

\subsection{Gürz Kaldırma}

Gürz, her yeri ya da yalnızca başı demirden ya da bakırdan yapılmış, sapı ağaçtan, demirden ya da bakırdan olabilen bir topuzdur. Türkçe adı 'bozdoğan'dır. Süvari / atlı ve piyade / yaya için olan çeşitleri vardır. Osmanlı Padişahları gürzü savaşlarda ve spor talimlerinde kullanmışlardır. Savaşmak için yapılan gürzler, spor için yapılan gürzlerden daha hafiftir ve yapılış biçimi farklıdır. Bazı kaynaklarda gürz veya topuz taşımanın asalet ve üstünlük göstergesi olduğu belirtilmiştir (https://www.tarihbilimi.gen.tr).

\subsection{Matrak}

İki kişi arasında bir gösteri gibi oynanan bir oyundur. Hareketler birbirine uyumlu, dans eder gibidir. Oyuncuların elinde tahta kılıç ve kalkan yerine de yuvarlak bir yastık bulunur. Oyunun amacı matrağı (üzerine post sarılmış tahta kılıç) rakibin kafasına vurabilmektir (Yurdayın, H. G. 1963: 2).

\subsection{Tomak}

Tomak oyunu Osmanlı Devleti'nin son iki yüz yılında oynanan saray oyunlarından biridir. Tomak oyunu, "tomak topu" ile oynanmaktadır. Tomak topu, içi kar keçesi ile doldurulmuş, yumruk büyüklüğündeki meşin topun, kamçı şeklinde sırımdan örülmüş bir sapa bağlanmasıyla yapılır. Tomak oyunu altışar kişilik iki takım arasında oynanmakla birlikte, bazı durumlarda oyuncu sayısı artırılır. Oyunculara birer tomak verilerek, oyunu idare eden çavuşun işareti ile oyun başlatılır. Oyuncular tomak topunu birer kamçı gibi kullanarak birbirlerine hamle yaparlar ve sırtlarına vurmaya çalışırlar. Her vuruşa hamle etmek denir, rakip oyuncular da tomak topunu sırtlarına vurdurmamak için kolları ile savunma yapar. Tomak topu sırtına vurulanlar oyun dışı kalır. Çabukluk, çeviklik ve becerinin geliştiği tomak oyununda rakibin sırt bölgesi dışına vurmak yasaktır (http://www.atasporlarivakfi.org).

\section{Modern Sporlar}

Türkiye'de spor, 16 spor kulübünün bir araya gelip örgütlenmesiyle 1923'te kurulan Türkiye İdman Cemiyetleri İttifakı, 1936'da kurulan, Türk Spor Kurumu ve 29 Haziran 1938 günlü 
kanunla kurulan Beden Terbiyesi Genel Müdürlüğü ile üç ayrı aşamadan geçmiştir. Genel müdürlük 1942'de Milli Eğitim Bakanlığı'na, 1960'da Başbakanlığa bağlanmış, 1969'da Gençlik ve Spor Bakanlığı kurulmuştur. 1989'da Gençlik ve Spor Genel Müdürlüğü tekrar başkanlığa bağlanarak 1991'de yeniden yapılandırılmıştır. 1974 ve 1975'te ilk kez Ankara, İstanbul ve Manisa'da spor akademileri açılmıştır (Emiroğlu, K. 2001: 557).

Modern sporlar, evrensel dili, üretim/tüketim modeli, dünya da etkili ekonomi ve sanayisi, geniş katılımlı taraftar kitlesi, demokratik ve kapsamlı örgütlenmesi, ön plana çıkardığı görselliği, spesifik tesis ve malzemesi, müsabaka öncesi ve sonrası yüksek performans zorunluluğu, teknik bilgi ve ekipman gerekliliği gibi daha pek çok faktörden geleneksel sporlardan ayrılmaktadır. Geçmişteki uygulamalardan çeşitli faktörlere bağlı olarak bazı değişikliklere uğrayarak günümüze kadar gelen geleneksel spor organizasyonları, günümüzün spor organizasyonları ile karşılaştırıldığında geçmişteki uygulamaları ile bugünküler arasında modern sporların özelliklerinde bazı değişim ve dönüşümler gözlenmiştir (Karahüseyinoğlu, 2008: 2).

Ülkemizde federasyonu bulunan spor dalları şöyle sıralanabilir: Karate, Atletizm, Kürek, Basketbol, Binicilik, Bisiklet, Boks, Buz hokeyi, Buz pateni, Jimnastik, Çim hokey, Eskrim, Futbol, Güreş, Golf, Kayak, Kızak, Judo ve kuraş, Halter, Hentbol, Masa tenisi, Kano ve Rafting, Badminton, Su topu, Modern pentatlon, Okçuluk, Rugby, Yüzme, Taekwondo, Tenis, Triatlon, Voleybol, Yelken, Bowling, Briç, Bovve, Dart, Bilardo, Dağcılık, Kickboks, Oryantiring, Atıcılık, Motosiklet, Muay thai, Otomobil sporları, Sualtı sporları, Wushudur.

Geçmişten günümüze Türk tarihinde önemli yere sahip spor dalları ve bu sporların genel özelliklerini belirlemek, bu spor dallarında başarıları ile iz bırakan Çorumlu sporcuları tanımak ve tanıtmak amacıyla gerçekleştirilen araştırmanın bu bölümünde; çeşitli spor dallarında başarıları ile iz bırakan Çorumlu sporcuların tespiti yapılmıştır. Türk sporcuların olimpiyat başarılarının incelenmesi amacıyla, bu konuda ulaşılabilen basılı tek kaynak olması nedeniyle, Türkiye Milli Olimpiyat Komitesi'nin 100. Yılına ithafen çıkarılan ve bir arşiv niteliği taşıyan, 'Türkiye Milli Olimpiyat Komitesi'nin 100. Yılı' adlı kitap taraması yapılmıştır. Yapılan taramada 1896'dan günümüze kadar 39 sporcunun altın madalya, 24 sporcunun gümüş, 28 sporcunun ise bronz madalya aldığı tespit edilmiştir. Yapılan incelemelerde güreş ve tekvando dallarında başarılı olan çok sayıda Çorumda doğmuş, yaşamış sporcu tespit edilmiştir. Çalışmanın sınırlandırılması amacıyla alanında ilklere imza atmış, duayen olarak nitelendirilen, olimpiyat başarışı elde etmiş aşağıda ismi verilen sporcuların görselleri üzerinde asamblaj çalışmalarının yapılmasına karar verilmiştir. Sanatsal asamblaj çalışmalarının yapılmasına karar verilen sporcuların kısa yaşam öyküleri aşağıda verilmiştir:

- Tevfik Kış: 10 Ağustos 1934 yılında Çorum'un Kargı İlçesine bağlı Pelitcik köyünde dünyaya gelmiştir. 1956 yılında güreşe başlamıştır. 1959 yılı İstanbul'da Balkan ikincisi olmuştur. 1959 yılı Beyrut' da Akdeniz Oyunları birincisi, 1960 yılı Roma Olimpiyatlarında birinci olmuştur. 1961 yılı Yokohama' da 87 Kg da Dünya dördüncüsü, 1962 yılı Toledo A.B.D. de Dünya birincisi, 1963 yılı Helsinki'de Dünya birincisi, 1965 yılı Tampera'da Dünya dördüncüsü, 1966 y1lı Toledo A.B.D. de Dünya ikincisi, 1966 yılı Essen Federal Almanya da Avrupa birincisi, 1967 yılı Minks S.S.C.B de Avrupa beşincisi olmuştur. 1968 yılında güreşi bırakmıştır (www.guresiyorum.com).

- Nazmi Avluca: 1975 yılında Çorum ili Kargı ilçesinde dünyaya gelmiştir. 1987 yılında Bolu güreş eğitim merkezinde güreşe başlamıştır. 1991 yılı Kanada da Yıldızlar Greko-romen stil $51 \mathrm{Kg}$ da Dünya yedincisi, 1992 y1lı İstanbul'da Dünya birincisi, 1994 y1lı İstanbul'da Ümitler Greko -Romen stil 74 Kg. da Avrupa birincisi, 1994 yılı Macaristan da Gençler Greko-Romen stil 74 Kg. da Dünya ikincisi, 1995 yılı İran'da Ümitler Greko-Romen stil 74 Kg. da Dünya üçüncüsü, 1996 yılı Budapeşte'de Avrupa birincisi, 1997 yılı Varşova'da Dünya altıncısı, 1998 yılı Minsk'de Avrupa üçüncüsü, 1998 yılı Gavle'de Dünya üçüncüsü, 1999 yılı Atina'da Dünya birincisi, 2001 y1lı İstanbul'da Avrupa üçüncüsü, 2004 yılı İsveç'de Avrupa birincisi, 2009 Herning Dünya 
Şampiyonası'nda birinci, 2008 Pekin Olimpiyatlarında üçüncülük dereceleri elde etmiştir. Gençlik ve spor Bakanlığında Müşavir olarak çalışmaktadır (www.guresiyorum.com).

- Adil Candemir: 1917 Hamamözü doğumlu güreşçilerimizden birisidir. 1948 Londra Olimpiyatlari $79 \mathrm{~kg}$ da ikinci, 1949 Avrupa Şampiyonasi (İstanbul) $87 \mathrm{~kg}$ da birinci, 1950 Dünya Grekoromen Güreş Şampiyonası $87 \mathrm{~kg}$ da ikinci olmuştur. 1951 yılında yapılan Helsinki'deki dünya şampiyonasında sakatlanan Adil Hoca güreşi bırakmıştır (www.msxlabs.org).

- Mahmut Atalay: Mahmut Atalay, bir dönem Dünya ve Olimpiyat şampiyonu olmuş, Türk Güreş Milli Takımı güreşçisidir. 1934'te Çorum'da dünyaya gelen Merhum Milli Güreşçi Mahmut Atalay, 1952 'de on sekiz yaşlarındayken güreşe başlamıştır. 25 yaşında milli takıma giren Atalay, Celal Atik ve Nasuh Akar gibi efsane güreşçilerimiz tarafından yetiştirilmiştir. 1961 yllına kadar 73 kilo, 1961'den kariyerinin sonuna kadar da 78 kiloda ve orta sıklette mücadele etmiştir. Ayrıca, güreşi bıraktıktan sonra güreş sporuna antrenör olarak katkıda bulunmuştur. $1964 \mathrm{Yaz}$ Olimpiyatları'nda serbest stilde bronz madalya ve 1968 Yaz Olimpiyatları'nda aynı stilde şampiyon olarak altın madalya kazanmıştır. Atalay 2004 yılında Ankara'da vefat etmiş̧ir (http://www.tgf.gov.tr).

Yukarıda belirtilen bu sporcuların görselleri üzerinde yapılacak sanatsal bir çalışma olan asamblaj tekniği; terimi ilk defa Jean Dubuffet tarafindan $1953^{`}$ te doğal veya hazır malzemelerin parçalarından oluşturulan sanat eserlerini tanımlamak için kullanılmıştır. Bazı eleştirmenler bu terimin, iki boyutlu olan kolajdan ayrı olarak sadece üç boyutlu nesneler için kullanılması gerektiğini ifade etseler de konuda ulaşılmış bir fikir birliği yoktur. Genel anlamıla asamblajın, fotomontajlardan mekan düzenlemelerine kadar geniş bir yelpazede yer alan sanat eserlerini kapsadığı söylenebilir (Chilvers, 1996).

Yukarıda belirtilen sporcuların ailelerinden ve medyadan edinilen görsellerinin asamblaj çalışmaya uygun hale getirilebilmesi için çözünürlüğünün ve baskı kalitesinin arttırılması amaciyla fotoğraflar üzerinde photoscape, reshade, protozoom, benvista, vector magic, photoshop vb programlar ile çalışılmıştır. Ayrıca birbirinden bağımsız fotoğraflar illüstrasyon ile Çorum'a uygun bir temada bir araya getirilmiştir. Hazırlanan fotoğrafların yüksek çözünürlükte $100 \times 70 \mathrm{~cm}$ ebadında, her biri için 36 şar adet ofset baskıları yapılmıştır. Tüm ön hazırlık işlemleri tamamlandıktan sonra, fotoğraf yüzeyi üzerinde kağıt rölyef (kağıt kabartma), giydirme, kolaj uygulamaları, perspektif kurallarına uygun olarak yapılmıştır. Asamblaj üzerinde uygulanan bu sanatsal teknikler şunlardır:

Kağıt rölyef: Kişinin seçtiği yüzey (kağıt, taş, alüminyum vb.) üzerine yapılan yükseltme ya da çökertme işine denir.

Kolaj: Bir karton üzerine yapıştırılan çeşitli kumaş, tahta, kâğıt vb. parçalarıyla yapılan resim.

Yüzey Giydirme Tekniği: Resim üzerindeki giysinin kumaş, renk, desen, şekil ve dikiş yönünde aynı özelliklerde olacak şekilde hazırlayarak resim üzerine yerleştirme işidir.

Aşağıdaki örnek görsellerde verilen detaylardaki gibi kesme, kretuarlama, yakma, kontör çekme, ütü topuzu ile kabartma, slikon ile montajlama işlemleri yapılarak çalışma tamamlanmıştır. Kağıt rölyefi tamamlanan çalışmaların giysileri dikilmiş, görseller üzerine giydirilmiş ve sunuma hazır hale getirilmiştir. Kağıt rölyef ve giydirme çalışmaları tamamlanan görseller paspartu ve çerçevesi tamamlanarak sunuma hazır hale getirilmiştir. Asamblaj çalışma detaylarına ilişkin örnekler aşağıda verilmiştir. 

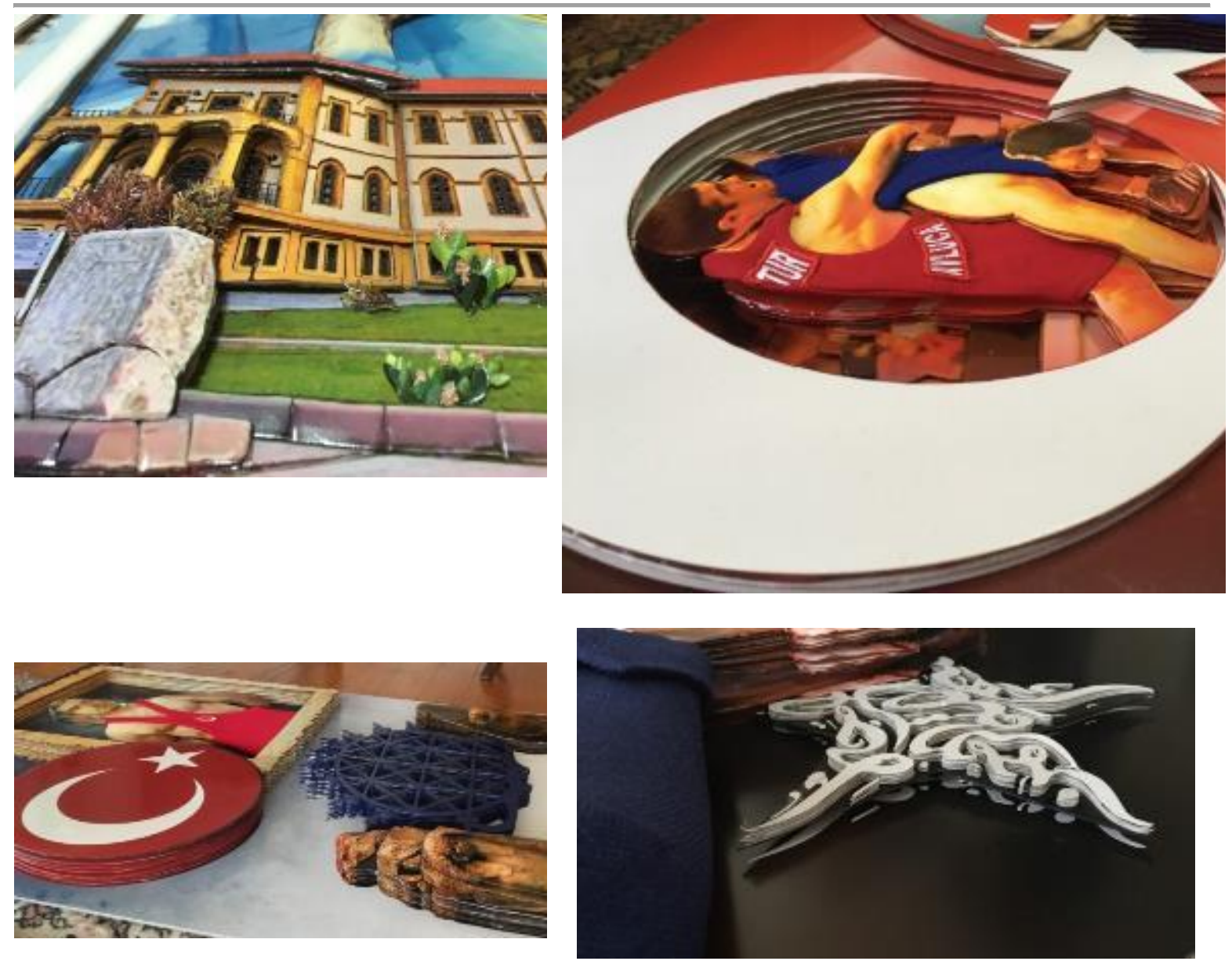

Resim 1: Asamblaj detay örnekleri

\section{Sonuç}

Geçmişten günümüze Türk tarihinde önemli yere sahip spor dalları ve bu sporların genel özelliklerini belirlemek; Çorumlu olup, ilgili spor dalındaki başarıları ile Türk spor tarihinde iz bırakmış sporcuları tanımak, tanıtmak ve yaşatmak amacıyla yürütülmüş bu araştırmanın ulaşılan sonuçları şunlardır:

1. Türkler çok köklü bir spor kültürüne sahiptir.

2. Türklerdeki göçebe kültürü, hayatta kalma zorunluluğu, avlanma ve savaşç1lık kültürleri sporun çok eski çağlardan gelerek sürekli gelişmesine neden olmuştur.

3. Türklerdeki göçebe kültürü ve sosyal hayatlarında atı çok fazla kullanmalarından dolayı, atlı sporlar gelişmiştir.

4. Türkler sporu sadece savaş taktiği ve hazırlığı olarak kullanmak yerine sosyal ve eğlence hayatına da dahil ederek oyunlaştırmışlardır.

5. Türklerin spor tarihi iki aşamalıdır:

Geleneksel sporlar: Geleneksel güreşler (aba güreşleri, şalvar güreşi, karakucak güreşleri, yağlı güreş, kuşak güreşleri), geleneksel atlı sporlar (binicilik, at yarışları, rahvan at yarışı, cirit, 
çöğen-polo, gökbörü), geleneksel kızak yarışları, okçuluk, avcılık, mızrak, labut atma, gürz kaldırma, matrak, tomak.

Modern sporlar: Karate, Atletizm, Kürek, Basketbol, Binicilik, Bisiklet, Boks, Buz hokeyi, Buz pateni, Jimnastik, Çim hokey, Eskrim, Futbol, Güreş, Golf, Kayak, Kızak, Judo ve kuraş, Halter, Hentbol, Masa tenisi, Kano ve Rafting, Badminton, Su topu, Modern pentatlon, Okçuluk, Rugby, Yüzme, Taekwondo, Tenis, Triatlon, Voleybol, Yelken, Bowling, Briç, Bovve, Dart, Bilardo, Dağcılık, Kickboks, Oryantiring, Atıc1lık, Motosiklet, Muay thai, Otomobil sporları, Sualtı sporları, Wushudur.

6. Geleneksel sporlarda günümüze kadar gelmeyi başaramamış ya da değişime uğramıştır.

7. Araştırma kapsamında erişilen, alanında uluslararası başarılara imza atmış Çorumlu sporcular arasından seçilen ve görselleri üzerinde sanatsal asamblaj çalışmalarının yapılmasına karar verilen sporcular ise şunlardır: Tevfik Kış, Nazmi Avluca, Adil Candemir, Mahmut Atalay.

8. Araştırma süresince hazırlanan sanatsal asamblaj çalışmalarının sonucunda ise aşağıdaki eserler elde edilmişti

Spor, kültürümüz tamamlayıcı unsurlarından biridir. Spor, toplumsal anlamda etkili bir eğitim unsurudur. Özellikle genç nesillerin, yapıcı, yaratıcı ve üretici olmasında, başarılarının artmasına, sosyal kaynaşma ve kültürel kalkınmaya çok büyük katkısı vardır. Spor, toplumların eğitim ve kültür düzeylerini gösteren önemli göstergelerden biridir. Bundan sonraki çalışmalarda farklı geleneksel Türk sporları ve sporcuları ile ilgili benzer çalışmaların yapılması önerilmektedir. Böylece, önemli kültürel miraslarımızdan biri olan Türk sporlarının ve başarılı Türk sporcularının hatırlatılması ve yaşatılmasının; hem kültürel mirasın ulusal ve uluslararası arenada tanıtılması, hem de genç neslin atalarından ilham alarak yeni başarılara adım atması konusunda katkılar sağlayacağı düşünülmektedir.
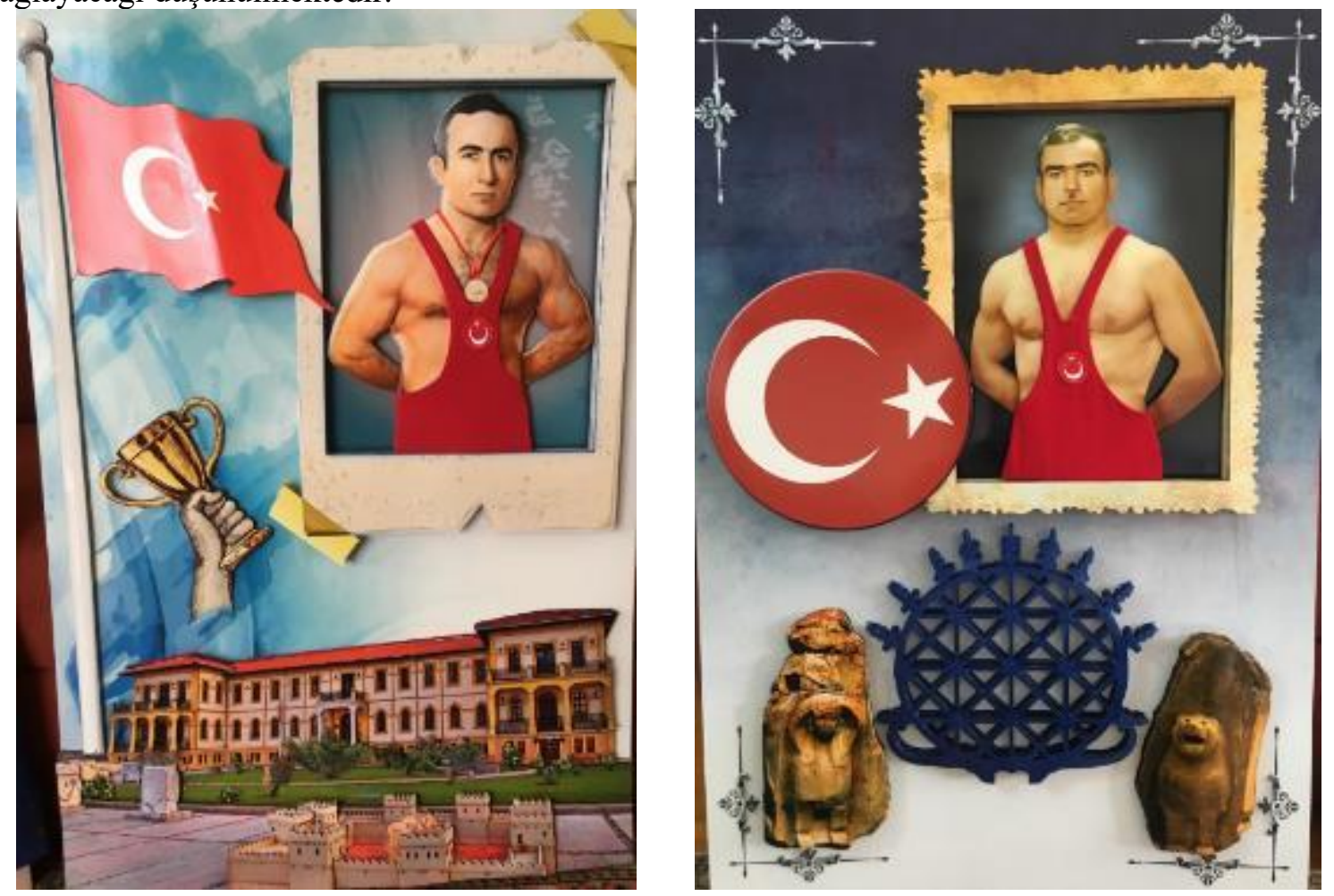
MAHMUT ATALAY

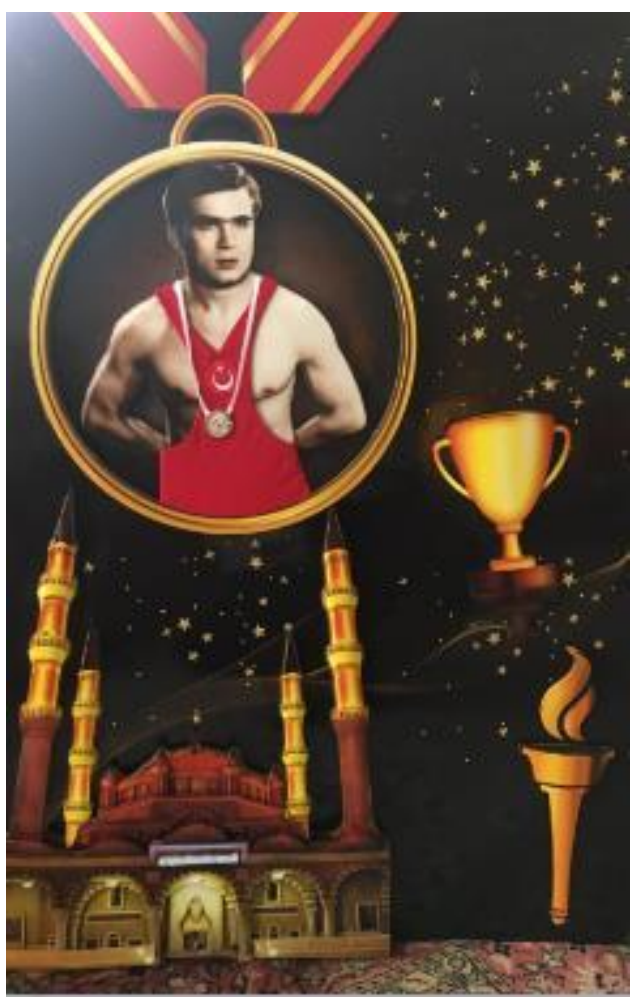

TEVFIKK KIŞ
ADIL CANDEMIR

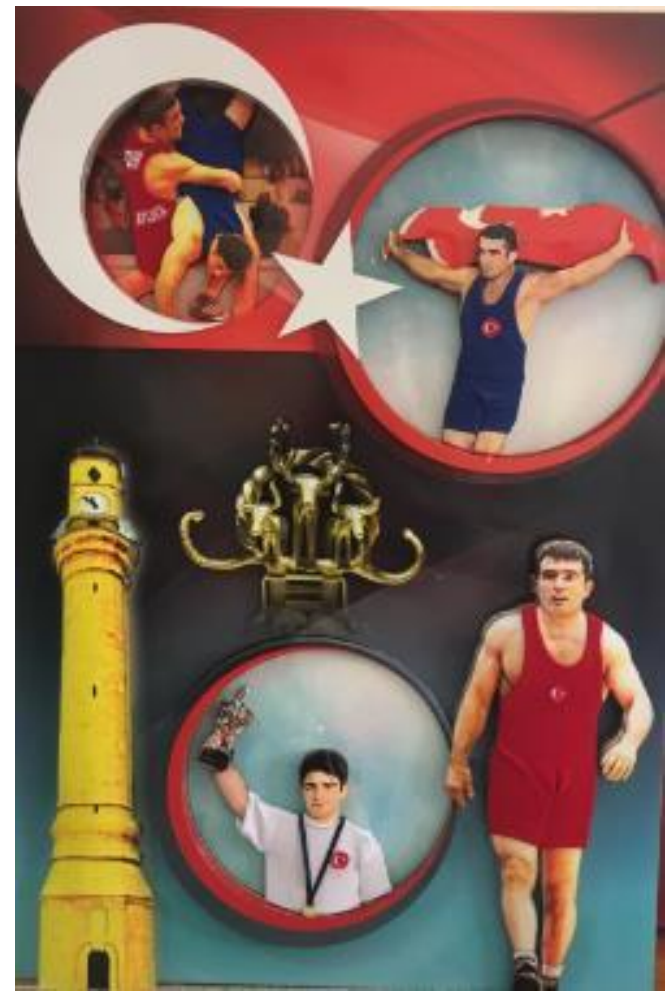

NAZMİ AVLUCA

Resim 2: Asamblaj çalışmalarının bitmiş şekli

\section{Kaynakça}

Alp, T. N. (1993). Tarih Boyunca Türk Toplumunda Silah Kavramı ve Osmanlı İmparatorluğu'nda Kullanılan Silahlar, Atatürk Kültür, Dil ve Tarih Yüksek Kurumu, Atatürk Kültür Merkezi Yayın1- (68), Ankara.

Ayan, D. (1997). Kültürel Geçişlilikte Polo / Çevgan Oyunu, Dördüncü Uluslararası Türk Kültürü Kongresi.

Bıyıklı, Y. (1993). Genç Güreşçi Yetiştirilmesi Konusunda Kamu Kuruluşlarının Rolü ve Bursa Örneği, Güreş İhtisas Kulübü Vakfi Yayınları, İstanbul.

Chilvers, I. (1996). The Concise Oxford Dictionary of Art \& Artists: Oxford University Press

Emiroğlu, K. (2001). Gündelik Hayatımızın Tarihi, Dost, Ankara, s.557.

Fişek, K. (1985). 100 Soruda Türkiye Spor Tarihi. 1. Baskı. İstanbul: Gerçek Matbaası.

Gezder, N. (1998). Geleneksel Sporlarımızdan Ata Sporu Cirit, Eser Ofset Matbaaacılık, 2. Bask1, Erzurum, s. 94.

Güven, Ö. (1992). Türklerde Spor Kültürü, Türk Tarih Kurumu Basım Evi, Ankara, s. 1-2, 27.

Güven, Ö. ve Ayan, D. (1996). Edebî Metinlerde Polo/Çevgân, Atatürk Kültür, Dil ve Tarih Yüksek Kurumu Bülteni, IX- 26-27.

Güleç, E. (1996), Türk Cirit Atı, Ankara, 1998, 16-15. 
Türk Spor Tarihinde Geleneksel Türk Sporkarı ve Çorumlu Sporcular - Asamblaj Tekniği... 1657

Günönü, G. (2015). 2012 Londra Olimpiyatlarının Medyaya Yansıması, Gazi Üniversitesi Sağl1k Bilimleri Enstitüsü, Yüksek Lisans Tezi.

Gürsoy, Ö. (1996). Güreş Öğretim Yöntemleri, Yeni Doğuş Matbaacılık, Ankara.

Huş, S. (1974). Av Hayvanları ve Avcılık, İstanbul Üniversitesi Orman Fakültesi Yayınları, İstanbul.

Ögel, B. (1989). Türk Mitolojisi Cilt I, Türk Tarih Kurumu Yayını: 102, Ankara

Öngel, H. B.(2001). Türk Kültür Tarihinde Spor, Kültür Bakanlığı Yayınları, 1. Baskı, Ankara

Özbay, G. (1999). Türklerde Spor Kültürü, Atatürk Kültür Merkezi Başkanlığı, s.191.

Kahraman, A. (1995), Osmanlı Devletinde Spor. T.C. Kültür Bakanlığı Yayınları.

Karahüseyinoğlu, M. Fatih. (2012). Küresel Eksende Türk Sporları, Kum Saati Yayın Dağıtım Ltd. Şti., İstanbul. s. 94.

Kepecioğlu, K. (1935). Türklerde Spor, Uludağ Üniversitesi Yayınları, 3, s.16-17.

Polga, İ. (1998). Milli Takın Seviyesindeki Greko-Romen ve Serbest Stil Türk Güreşçilerin SosyoEkonomik Yapılarının Araştırılması, Gazi Üniversitesi Sağlık Bilimleri Enstitüsü, Yüksek Lisans Tezi.

Sümer, F. (1983), Türklerde Atçllık ve Binicilik, Türk Dünyası Araştırmaları, 1-2

Şükrü, Y. (1987). İslam'da Avcılık, Osman ÇELİK (Yayına hazırlayan), Musa Bilgi (Sadeleştiren ve Özetleyen), Ankara.

Türkmen, M. (1996). Türklerde Geleneksel Atlı Sporların Yapılışı, M.Ü. Sağlık Bilimleri Enstitüsü, Doktora Tezi.

Toyga, Y. (1990), Türk Spor Tarihine Genel Bakış, Gençlik ve Spor Genel Müdürlüğü Yayınları, Ankara, s. 1-23.

Yurdayın, H. G. (1963). Matrakçı Nasuh, Ankara Üniversitesi İlahiyat Fakültesi Yayınları: XLIII.

https://www.tarihbilimi.gen.tr/makale/gurz-kaldirma/(Erişim Tarihi: 10.08.2019)

http://www.atasporlarivakfi.org/ata-sporlarimiz/tomak/(Erişim Tarihi: 10.08.2019)

http://www.guresiyorum.com (Erişim Tarihi: 10.12.2017)

http://www.msxlabs.org (Erişim Tarihi: 10.01.2018)

http://www.tgf.gov.tr (Erişim Tarihi: 08.01.2018) 